\title{
Short-chain perfluoroalkyl acids: environmental concerns and a regulatory strategy under REACH
}

\author{
Stephan Brendel ${ }^{*} \mathbb{B}$, Éva Fetter, Claudia Staude, Lena Vierke and Annegret Biegel-Engler
}

\begin{abstract}
Background: Short-chain PFASs (per-and polyfluoroalkyl substances) are widely used as alternatives to long-chain PFASs. Long-chain PFASs become gradually regulated under REACH (EC No. 1907/2006) and other international regulations, due to having persistent, bioaccumulative and toxic properties and/or being toxic for reproduction. The increasingly used short-chain PFASs are assumed to have a lower bioaccumulation potential. Nonetheless, they have other properties of concern and are already widely distributed in the environment, also in remote regions. The REACH Regulation does not directly address these emerging properties of concern, complicating the implementation of regulatory measures. Therefore, this study illustrates these environmental concerns and provides a strategy for a regulation of short-chain PFASs within REACH.

Results: Short-chain PFASs have a high mobility in soil and water, and final degradation products are extremely persistent. This results in a fast distribution to water resources, and consequently, also to a contamination of drinking water resources. Once emitted, short-chain PFASs remain in the environment. A lack of appropriate water treatment technologies results in everlasting background concentrations in the environment, and thus, organisms are permanently and poorly reversibly exposed. Considering such permanent exposure, it is very difficult to estimate long-term adverse effects in organisms. Short-chain PFASs enrich in edible parts of plants and the accumulation in food chains is unknown. Regarding these concerns and uncertainties, especially with respect to the precautionary principle, shortchain PFASs are of equivalent concern to PBT substances. Therefore, they should be identified as substances of very high concern (SVHC) under REACH. The SVHC identification should be followed by a restriction under REACH, which is the most efficient way to minimize the environmental and human exposure of short-chain PFASs in the European Union.

Conclusion: Due to an increasing use of short-chain PFASs, an effective regulation is urgently needed. The concerns of short-chain PFASs do not match the "classical" concerns as defined under REACH, but are not of minor concern. Therefore, it is of advantage to clearly define the concerns of short-chain PFASs. This might facilitate the following restriction process under REACH.
\end{abstract}

Keywords: REACH, SVHC, PFASs, Candidate list, Restriction, Regulation, Per- and polyfluoroalkyl substances, PFAAs

\section{Background}

Some representatives of per- and polyfluoroalkyl substances (PFASs) are highly stable organic compounds, due to the $\mathrm{C}-\mathrm{F}$ bond being one of the strongest in organic chemistry [1]. Compared to hydrocarbons, PFASs have

\footnotetext{
*Correspondence: Stephan.brendel@uba.de German Environment Agency, Wörlitzer Platz 1, 06844 Dessau-Roßlau, Germany
}

enhanced technical properties, such as a higher surface activity and better dielectric properties, and possess at the same time a higher thermal stability, an increased chemical resistance and a physiological inertness [2]. Due to these properties, PFASs are well suited for manifold applications and have been used extensively in various industrial and consumer applications since the 1950s, e.g., impregnation of textiles, paper, hard metal plating, 
in paints, the production of fluoropolymers, etc. [3, 4]. During the production and life cycle of the products, a certain fraction of PFASs is inevitably emitted into the environment (e.g., [5]). Many commonly used PFASs can degrade under environmentally relevant conditions to perfluoroalkyl acids (PFAAs), regarded as final degradation products (e.g., [6]). Besides the direct emission of PFAAs, e.g., from production and life cycle of certain fluoropolymers, indirect emissions via degradation of the precursor substances are of high relevance regarding the global emissions [7]. Also, side-chain fluorinated polymers, in particular the group of side-chain fluorotelomerbased polymers, were shown to be degraded to PFAAs under environmental conditions in the range of decades to centuries [8] and are therefore considered to be precursors. As highly persistent final degradation products of many other PFASs, PFAAs are a relevant group regarding environmental and human exposure, even though being a small substance group within the whole PFASs group, consisting of at least 3000 substances [9].

The concern of possible risks of PFAAs to the environment and human health was broadly unrecognized until the turn of the millennium, when two groups of PFAAs, long-chain perfluoroalkyl carboxylic acids and long-chain perfluoroalkane sulfonic acids, have been shown to be ubiquitously present in biota and humans (e.g., $[10,11])$. Since becoming aware of the ubiquitous distribution and the hazardous properties (see [12]) of long-chain PFASs (i.e., long-chain PFAAs and their precursors), voluntary measures of manufacturers and regulatory action have been taken place to reduce the emissions. Perfluorooctane sulfonic acid (PFOS), its salts and perfluorooctane sulfonyl fluoride (PFOSF) are listed as persistent organic pollutant (POP) under the Stockholm Convention and perfluorooctanoic acid (PFOA) and related precursors are proposed as POP. Under the European Chemicals Regulation (REACH EC No. 1907/2006), several longchain perfluoroalkyl carboxylic acids $\left(\mathrm{C}_{8}-\mathrm{C}_{14}\right)$ and the long-chain perfluorohexane sulfonic acid are identified as substances of very high concern (SVHC) and included in the REACH candidate list. In the EU restriction, proposals for the perfluoroalkyl carboxylic acids on the candidate list are in progress, but only implemented for PFOA its salts and related substances up to the present. In summary, global measures to ban long-chain PFAAs of concern are ongoing and need to be continued.

With the regulation of long-chain PFASs and due to voluntary measures, non-regulated PFASs have been more extensively used as alternatives. Information of these replacements are not easily accessible, however, it is known that short-chain PFASs (i.e., short-chain PFAAs and respective precursors, see Fig. 1 for terminology) are important and broadly used alternatives [13]. Due to historical emissions mainly as unintended by-products during the manufacturing of long chain PFASs in the past, short-chain PFASs are already present in environmental compartments [7, 14]. The replacement of longchain PFASs with short-chain PFASs and in general other PFASs is highly criticized [15-17], as short-chain PFASs have also relevant properties of concern.

\begin{tabular}{|c|c|}
\hline $\begin{array}{l}\text { Perfluoroalkane sulfonic acids } \\
\text { Long-chain: } n \geq 6 \\
\text { Short-chain: } n<6 \\
\text { Example short-chain representative: } \\
\text { PFBS }(n=4)\end{array}$ & 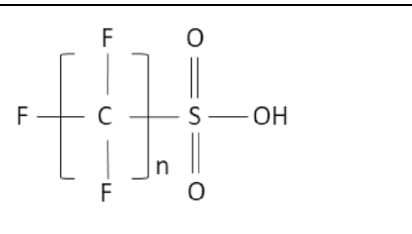 \\
\hline $\begin{array}{l}\text { Perfluoroalkyl carboxylic acids } \\
\text { Long-chain: } n \geq 7 \\
\text { Short-chain: } n<7 \\
\text { Example short-chain representatives: } \\
\text { PFBA }(n=3), \text { PFHxA }(n=5)\end{array}$ & $\mathrm{F}-\left[\begin{array}{c}\left.\right|^{\mathrm{F}} \\
\mathrm{C} \\
\left.\right|_{\mathrm{F}}\end{array}\right]_{\mathrm{n}}$ \\
\hline $\begin{array}{l}\text { Example of short-chain precursors } \\
4: 2 \text { fluorotelomer alcohol }(n=4) \\
6: 2 \text { fluorotelomer alcohol }(n=6)\end{array}$ & $\mathrm{F}-\left[\begin{array}{c}\mathrm{F} \\
\mathrm{C} \\
\mid \mathrm{F}\end{array}\right] \underbrace{\mathrm{H}}_{\text {non-fluorinated moiety }}$ \\
\hline
\end{tabular}

Fig. 1 Terminology of per- and polyfluoroalkyl substances 
Long- and short-chain PFAAs were originally distinguished, since short-chain PFAAs are assumed to have a lower bioaccumulation potential and improved environmental properties compared to long-chain PFAAs $[3,18]$. However, short-chain PFAAs are as persistent as long-chain PFAAs have different, but not less alarming properties of concern, and are already widely distributed in the environment [e.g., 19-27]. The awareness of these concerns needs to be raised to obtain a fast regulation of short-chain PFASs. Therefore, this study (i) summarizes and highlights the concerns of short-chain PFAAs, (ii) investigates the need for a regulation and (iii) provides a strategy for how a regulation could be implemented in $\mathrm{REACH}$.

\section{Results and discussion}

\section{Uses and sources of environmental exposure}

According to the publicly available information on REACH registrations, short-chain PFAAs, e.g., PFBA (perfluorobutanoic acid), PFBS (perfluorobutanesulfonic acid) and PFHxA (perfluorohexanoic acid) have not been registered so far. The last registration deadline under REACH for substances which are manufactured or imported between one and 100 tons per year is 31 May 2018. However, registration obligations do not include substances in imported articles. In contrast to the shortchain PFAAs, various short-chain precursor substances are registered in high tonnages (> 100 tons per annum) and are mainly used for manufacturing polymers. Those polymers may most likely have wide dispersive uses. In general, short-chain PFASs can substitute long-chain PFASs in manifold applications [28]. Therefore, they are used comparably to long-chain PFASs in many consumer products and industrial applications requiring inert or repellent characteristics. Due to a partially limited technical performance in comparison with long-chain PFASs, higher amounts of short-chain PFASs are usually used in compensation (e.g., in wax and polish) [28]. During the production and life cycle of the products, inevitably releases of short-chain PFASs into the aquatic and terrestrial environment occur [29]. There are vast amounts of applications, but only scarce information on uses of short-chain PFASs. Additionally, the degradation of sidechain fluorinated polymers might contribute significantly to emissions of short-chain PFASs in the long-term, as demonstrated by an environmental fate modeling analysis by $\mathrm{Li}$ et al. [30]. Besides degradation of the polymers in the long-term, non-bound residues can easily reach the environment and may thus contribute to future releases $[29,30]$. Due to the hundreds of various precursors, assessing the uses of all precursors is nearly impossible. The Swedish Chemicals Agency [4], the Norwegian Environment Agency [31] and the Danish Ministry of the
Environment [32] provided detailed information on the use of short-chain PFASs to the extent possible. In the following, information for some use areas is summarized.

In recent years, surfactants in foam-based fire-fighting agents, used to extinguish flammable liquids or gases, shifted from long-chain PFASs (mainly C8-based) to short-chain PFASs (mainly C6-based). The stability and surface-active properties of PFASs enable a film formation on top of burning liquids, extinguishing the fire and preventing burn back. Nowadays, a number of foambased fire-fighting agents contain short-chain PFASs. The use of fire-fighting agents results in direct contaminations of the environment when there is no possibility of collecting the fire water and subsequent disposal [33, 34].

Textiles, leather, carpet, apparel, and upholstery are desired to be oil, water and dirt repellent. For some papers and food contact materials, greaseproof properties are required. Therefore, these items can be impregnated with side-chain fluorinated polymers, consisting of non-fluorinated carbon backbones connected to shortchain PFAS side-chains such as fluorotelomer alcohols.

Short-chain PFASs are furthermore used for example as mist suppressing agents in hard metal-plating [35], in the electronic industry due to insulating and water repellent properties [36], in cosmetic products to make the products oil and water repellent [37], in paints and inks to improve wetting, smoothness and flow [36], in medical devices [4] and the oil production [32].

\section{Overview of concerns of short-chain PFAAs}

This section specifies concerns attributed in general to short-chain PFAAs. The properties of concerns only attributed to certain PFAAs or precursor substances are not addressed. However, precursors share the common concern of degradation to short-chain PFAAs as final degradation products. It is therefore possible to include precursors in a regulation of short-chain PFAAs (see "Strategy for regulation of short-chain PFASs under REACH").

\section{Short-chain PFAAs are extremely persistent}

Based on the high energy of the carbon-fluorine bond [2], it can be assumed that short-chain PFAAs are extremely persistent similar to the persistence of longchain PFAAs $[38,39]$. They do not undergo abiotic or biotic degradation at all under environmental conditions and are considered highly stable transformation products in which several precursors ultimately degrade into $[13,40]$. This extreme persistence is regarded as an incalculable hazard itself, as short-chain PFAAs will stay in the environment for decades to centuries [41]. The possible risks of such extremely persistent organic fluorochemicals for humans and the environment have been 
emphasized by leading scientists [16, 17]. Each released PFAS molecule remains in the environment, meaning that it is impossible to reverse exposure. Thus, levels of these substances will most probably increase over time in certain compartments. As a consequence, long-term effects on humans and wildlife may be possible in the future, when certain effect thresholds are reached.

\section{Short-chain PFAAs have a low adsorption potential and are very mobile}

The determination of the physicochemical properties of short-chain PFAAs requires, due to the unusual substance properties, specific methods. Estimates of the physicochemical properties are available (PFBS, PFBA and PFHxA [42, 43]: $\log K_{\text {ow }}$ (neutral form) $=2.82-4.6$, water solubility $>20 \mathrm{~g} / \mathrm{L}, \log K_{\text {oa }}=6-6.7, \mathrm{pK}_{\mathrm{a}}<1, \log$ $\left.K_{\mathrm{oc}}: 2.7-3.6\right)$, showing that short-chain PFAAs are very mobile, which is also confirmed by their environmental distribution $[44,45]$. Due to this mobility short-chain PFAAs effectively reach water bodies which is of special concern regarding human exposure: Drinking water resources are highly sensitive to contamination with short-chain PFAAs $[19,46]$. Due to the low adsorption potential, short-chain PFAAs will not bind to particles and stay mainly dissolved in the water phase.

\section{In a larger scale, once emitted short-chain PFAAs can only hardly be removed from water}

Long-chain PFAAs can be removed from water with activated carbon filters. However, this is not as effective for short-chain PFAAs due to the low adsorption potential [47]. Hence, at a large scale short-chain PFAAs can only hardly, if at all, be removed from the environment with the main methods available today [46, 48, 49]. Some promising methods are very costly and just applied at a laboratory scale [50]. The absence of effective measures on a larger scale is problematic in particular with regard to contaminated drinking water reservoirs. Since shortchain PFAAs are not expected to degrade chemically and biologically, the concentrations in contaminated areas will only decline with a further spatial distribution, provided that no further release occurs.

\section{Short-chain PFAAs have the potential for long-range transport. Already today, short-chain PFAAs are monitored in remote regions and show $a$ wide spread distribution in biotic and abiotic compartments}

Due to the high mobility caused by the high aqueous solubility and relatively low adsorption potential of shortchain PFAAs, they have a higher potential for long-range transport compared to the long-chain homologues [43]. Additionally, volatile precursors are likely to be transported to remote regions via the atmosphere and then being degraded to short-chain PFAAs. Monitoring data show that already today short-chain PFAAs are present in remote areas $[20,51,52]$ and have a wide spread distribution in biotic and abiotic compartments. Table 1 shows examples of monitoring data from Europe. In a few cases, increasing concentrations of shortchain PFAAs in the environment and biota are already observed; for example, for PFBS in dolphins from the South China Sea [53], for PFHxA in water samples near a fluoropolymer production plant in Japan [54] and for PFBA in snow from remote regions in the European Alps $[25,52]$. As demonstrated in a recent review by Land et al. [55], a generalized prediction of temporal trends in environmental concentrations of short-chain PFAAs is currently not feasible due to limited monitoring data and insignificant time trends shown in most of the studies. Historical releases of short chain PFASs are hard to quantify [7]. Because the substances are not degradable, historical releases, i.e., as unintended by-products during the manufacturing of long chain PFASs contributed to the environmental stocks to a reasonable amount and impede the observation of significant trends. However, due to the phase-out of long-chain PFASs [18, 56], manufacturing and use of short-chain PFAAs and related substances are very likely to further increase in the near future. Thus, emissions of short-chain PFAAs will increase as well. Along with the expected increasing emissions, short-chain PFAAs will further enrich in the environment leading to increased background concentration levels, in the long-term especially in the aquatic systems [57].

\section{The permanent exposure to short-chain PFAAs results in continuous and poorly reversible concentrations in organisms. There is a risk of adverse effects on humans and the environment, which will rise with increasing exposure}

Considering that the exposure to short-chain PFAAs is unlikely to be stopped shortly, there will be increasing continuous and poorly reversible environmental background concentrations of short-chain PFAAs. Consequently, organisms and humans will be permanently exposed to short-chain PFAAs, resulting in continuous and poorly reversible internal concentrations. The poorly reversible internal concentrations in organisms are caused by the persistence of short-chain PFAAs and their continuous presence in the environment. Therefore, the organismal elimination efficiencies are of secondary relevance. This becomes more evident when considering that the half-lives of short-chain PFAAs in the environment exceed their half-lives in the organisms by far. Cousins et al. [41] addresses this approach in more detail, showing exemplary that the contamination of drinking 
Table 1 Example monitoring data from Europe regarding PFBS, PFBA and PFHxA

\begin{tabular}{|c|c|c|}
\hline Sampling & Short-chain PFAA and concentration ${ }^{a}$ & Reference/sampling year \\
\hline \multicolumn{3}{|l|}{ Tab water $[\mathrm{ng} / \mathrm{L}]$} \\
\hline \multirow[t]{2}{*}{ France, 8 locations } & PFBS: $3.2(32 \%) ;$ & [19] \\
\hline & PFHXA: nd & Sampling year: 2014 \\
\hline \multirow[t]{3}{*}{ Germany, 26 locations } & PFBS: 2.7 (42\%) & {$[21]$} \\
\hline & PFHxA: $2(23 \%)$ & \\
\hline & PFBA 2 (19\%) & \\
\hline \multirow[t]{3}{*}{ Spain, 84 locations } & PFBA: 10 (52\%) & {$[22]$} \\
\hline & PFHxA: 4.7 (18\%) & Sampling year: 2010-2011 \\
\hline & PFBS: 8.3 (35\%) & \\
\hline \multicolumn{3}{|l|}{ Surface water [ng/L] } \\
\hline \multirow[t]{3}{*}{ Spain, Ebro } & PFBA: $35.2(58 \%)$ & [23] \\
\hline & PFHxA: 1.7 (8\%) & Sampling year: 2010 \\
\hline & PFBS: nd & \\
\hline \multirow[t]{3}{*}{ Spain, Guadalquivir } & PFBA: $214.3(92 \%)$ & \\
\hline & PFHxA: nd & \\
\hline & PFBS: 10.1 (8\%) & \\
\hline \multirow[t]{3}{*}{ Germany, Elbe } & PFBA: 2.6 (100\%) & [24] \\
\hline & PFBS: 7.5 (100\%) & Sampling year: 2015 \\
\hline & PFHxA: 1.5 (100\%) & \\
\hline \multirow[t]{3}{*}{ Germany, Saale } & PFBA: 0.5 (100\%) & \\
\hline & PFBS: 4.3 (100\%) & \\
\hline & PFHXA: 4 (100\%) & \\
\hline \multicolumn{3}{|l|}{ Snow $[n g / L]$} \\
\hline \multirow[t]{2}{*}{ European Alps } & PFBA: 0.69 & {$[25]$} \\
\hline & PFHXA: 0.06 & Sampling year: 2008 \\
\hline \multicolumn{3}{|l|}{ Sediments [ng/g dw] } \\
\hline \multirow[t]{2}{*}{ Baltic sea } & PFBS: 0.00017 (75\%) & {$[26]$} \\
\hline & PFHXA: 0.115 (100\%) & Sampling year: 2013-2014 \\
\hline \multicolumn{3}{|l|}{ Organisms [ng/g ww] } \\
\hline Baltic sea & & {$[26]$} \\
\hline Zooplankton & PFBS/PFHXA: nd & Sampling year: 2013-2014 \\
\hline Herring & PFBS/PFHXA: nd & \\
\hline Sprat & PFBS/PFHXA: nd & \\
\hline \multirow[t]{2}{*}{ Guillemot egg } & PFBS: 0.0035 (100\%) & \\
\hline & PFHxA: 0.0026 (50\%) & \\
\hline Ingolstadt, Germany & & {$[27]$} \\
\hline \multirow[t]{3}{*}{ Wild boar } & PFHXA: 0.49 (66\%) & Sampling year: 2011-2012 \\
\hline & PFBA: $0.73(100 \%)$ & \\
\hline & PFBS: 0.25 (53\%) & \\
\hline Svalbard, Norway & & {$[20]$} \\
\hline Reindeer & PFBA: 0.42 (56\%) & \\
\hline Ebro, Spain & & [23] \\
\hline \multirow[t]{3}{*}{ Fish } & PFBS: 4.9 (69\%) & Sampling year: 2010 \\
\hline & PFBA: 0.6 (31\%) & \\
\hline & PFHxA: 268.4 (56\%) & \\
\hline
\end{tabular}

${ }^{a}$ Mean values, including frequency detected 
water resources with short-chain PFAAs leads to a poorly reversible exposure in humans, comparably to a contamination with long-chain PFAAs. Due to the high mobility of short-chain PFAAs and the missing suitable water treatment technologies for drinking water, short-chain PFAAs will remain in the water resources over time (this scenario proves true, see "Case example Rastatt"). This results in a permanent exposure via drinking water, independently of the elimination half-lives of short-chain PFAAs.

Nevertheless, elimination half-lives of short-chain PFAAs are non-negligible: Depending on the species, they range from a couple of hours to several days in some mammals [58-60], with longer half-lives in humans (e.g., 30 days for PFHxA [61]). The elimination half-lives are shorter compared to some long-chain homologues, but nevertheless of concern, as short-chain PFAAs will still remain in organisms with continuous exposure. Some short-chain PFAAs have considerable protein binding potentials $[62,63]$. A high protein binding potential is of toxicokinetical relevance: the blood can easily distribute short-chain PFAAs within the body resulting in a potential to enrich particularly in blood rich tissues. Data from the exposure of mammals show that short-chain PFAAs can be widely distributed in the organism $[64,65]$.

Possible adverse effects, especially long-term effects, caused by a high protein binding potential are uncertain. In general, there is a high level of uncertainty, if the permanent exposure with low concentrations of short-chain PFAAs may cause adverse effects in organisms. There is insufficient data on the toxic properties of short-chain PFAAs [66], and therefore, sub-lethal long-term effects cannot be excluded. There might be unconsidered sensible organisms, certain development stages or effects on multiple generations, being not considered when assessing the toxicity of short-chain PFAAs. Mixture toxicity of different PFASs or the toxicity of PFASs in combination with natural and anthropogenic stressors is largely unknown [57].

\section{The distribution of short-chain PFAAs in terrestrial systems and along food chains is unknown. Short-chain PFAAs are known to enrich in edible parts of plants}

Short-chain PFAAs are known to enrich in plants and due to their high water solubility and low adsorption potential, especially in leaves and fruits [67-69]. This enrichment in the edible parts of plants is higher compared to long-chain PFAAs and might pose a risk regarding a distribution along the food chain, which has not yet been investigated. In contaminated soil, especially in former arable land, the accumulation in the edible parts of plants is of concern due to human exposure (exemplary shown in "Case example Rastatt"). Field studies do not allow drawing conclusions on distributions of short-chain PFAAs along the food chains. Especially, the accumulation in terrestrial organisms, as shown for longchain PFAAs [70], cannot be excluded [71].

\section{Case example Rastatt}

In the surroundings of Rastatt (Baden-Wuerttemberg, Germany), 480 hectares of former arable land are contaminated with short-chain PFAAs and precursors. The pollution was detected in 2013 and has probably been caused by the longstanding application of compost mixed with sludge from paper production, contaminated with various precursors. Over time, the precursors contained in the soil degraded to short-chain PFAAs and were enriched in plants. Local authorities derived thresholds for short-chain PFAAs in food (in the $\mu \mathrm{g} / \mathrm{kg}$ range) [72], based on guidance values for drinking water [73]. Pre-harvest monitoring showed that the concentration of short-chain PFAAs in some crops exceeded these thresholds, preventing the use as food. Crops enriching high amounts of short-chain PFASs are recommended not to be cultivated for consumption on these contaminated fields (e.g.,asparaguses, strawberries and other vegetables). Despite the recommendations for cultivation, threshold values are in parts exceeded to date. This might be due to a strong influence of insufficiently predictable abiotic factors, such as organic carbon content, on the enrichment of short-chain PFASs in plants [74]. Over time, the very mobile short-chain PFASs and precursors in the soil also wash out into the groundwater. Irrigating crops with contaminated water are causing further emissions to soil and uptake into plants. Two groundwater wells for drinking water production had to be closed [72].

For several years, the dimension of the contamination and the problems arising with the contamination of short-chain PFASs has not been recognized. Estimations addressing all adverse environmental effects and socioeconomic costs resulting from the contamination are not available, but according to information given by the water work solely the cost for water treatment with charcoal filters amounts to several million Euros. Until now, no practicable solution for removing the short-chain PFASs from the soil or groundwater has been found. Effective solutions, such as a removal and replacement of the top soil or "pump and treat" methods, would be far too expensive. Furthermore, there are still high concentrations of short-chain PFASs and unknown precursors contained in the soil and there is no applicable solution for stopping them from reaching the groundwater. Research to find an appropriate solution is ongoing.

This Rastatt case clearly shows that once emitted to the environment, short-chain PFAAs cause irreversible contaminations, and thus causing high socio-economic costs and threats to man and environment. Besides Rastatt, 
there is a large scale contamination of drinking water with short-chain PFASs in Uppsala known. The contamination in Sweden is mainly caused by the use of aqueous film forming fire-fighting foams at a military airport [33].

\section{Strategy for regulation of short-chain PFASs under REACH}

PFAAs themselves are not produced in high tonnages. Primarily manifold precursor substances degrading in the environment to PFAAs are responsible for their emission to the environment and subsequently to humans. Those precursor substances are defined by a similar length of the perfluorinated carbon chain compared to the shortchain PFASs, connected to a non-fluorinated moiety (see Fig. 1).

A regulation of every single precursor is impracticable due to the unknown but likely vast amount of precursors on the market. For an effective regulatory measure, it is mandatory to address both PFAAs and their precursor substances, considering also emissions from imported articles. These considerations have already been outlined by Vierke et al. [39] regarding the long-chain perfluoroalkyl carboxylic acid PFOA. Precursors registered under REACH are mainly used for manufacturing polymers according to industry. Those polymers (i.e., sidechain fluorinated polymers) contain unbound residues of PFASs precursors or the polymers may breakdown over time and release PFAS precursors [8]. Thus, polymers are included in such a regulation as well.

In short, as a first step identification as SVHC according to Article 57 of the REACH regulation needs to be considered. Such substances become included in the REACH candidate list. Article 57 of the REACH Regulation allows to include substances on the candidate list that (i) are classified as carcinogenic, mutagenic or toxic for reproduction (CMR) category $1 \mathrm{~A}$ or $1 \mathrm{~B}$, (ii) have persistent, bioaccumulative and toxic (PBT) or (iii) very persistent and very bioaccumulative ( $\mathrm{vPvB}$ ) properties according to REACH (Annex XIII), or (iv) have an equivalent level of concern as CMR or $\mathrm{PBT} / \mathrm{vPvB}$ substances. The inclusion of a substance in the candidate list results in obligations for the manufacturer to provide information to downstream users and to consumers (if $>0.1 \%$ proportion in articles). This regulatory measure alone is not sufficient to control the emissions of shortchain PFASs. But the inclusion into the candidate list is a strong signal itself since it contains all substances of very high concern identified within the EU. For substances on the candidate list REACH foresees authorisation as the regulatory measure. In such case, using the substance is only allowed if authorization was granted. However, an authorisation does apply only for the substance itself and does not include any precursor substances. Furthermore, the authorisation procedure does not include imported articles, probably contributing to the emissions of shortchain PFASs in Europe. Consequently, starting the authorisation procedure would not constitute an effective risk management option. A restriction (Article 67) can cover the placing of a substance on the market, the content of a substance in (imported) articles, the use of such a substance on its own or in a mixture and respective precursors. Thus, a general restriction can address all relevant emission routes and is considered the appropriate regulatory measure for short-chain PFASs under $\mathrm{REACH}$. To decide if certain exemptions might be appropriate, further detailed information on uses and alternatives are necessary. Once in force, the restriction is valid for the European Economic Area (EEA), having a population of more than 500 million people.

\section{The equivalent level of concern}

With the current knowledge, short-chain PFASs seem not to fulfill the bioaccumulation or toxicity criteria of REACH Annex XIII. Due to the special properties of short-chain PFASs, they might not fulfill the "classical" properties of concern of SVHCs, being clearly defined within Article 57(d and e) of the REACH Regulation. However, given the properties of concern (see "Overview of concerns of short-chain PFAAs") and the already existing pollutions (see "Case example Rastatt"), there is an unequivocal need for regulation of short-chain PFASs. Within the REACH Regulation, it is possible to identify substances as SVHC that have an equivalent level of concern compared to CMR or PBT/vPvB substances, as defined in article 57(f) (see "Strategy for regulation of short-chain PFASs under REACH"). So far, the equivalent level of concern approach is applied for endocrine disrupting chemicals, sensitisers and specific target organ toxicity after repeated exposure only. However, in our opinion short-chain PFASs are also of equivalent level of concern compared to $\mathrm{PBT} / \mathrm{vPvB}$ substances and can be identified as SVHC for the following reasons:

Article 1 of the REACH Regulation states that the provisions of the REACH Regulation are underpinned by the precautionary principle. The realization of the precautionary principle is apparent when looking at the $\mathrm{vPvB}$ criteria for the SVHC identification (Article 57(e)). Even though a substance does not cause any toxic effect, it can be identified as SVHC because it is due to its intrinsic properties expected to remain in the environment and to accumulate in organisms. The reasoning is that (i) the level of uncertainty in identifying long-term effects cannot be estimated with sufficient accuracy (vB) and (ii) consequences of an underestimation of adverse effects are not easily reversible by regulatory action (vP), i.e., the effect is occurring or is likely to occur at a certain point in time, and even if there is immediate regulatory 


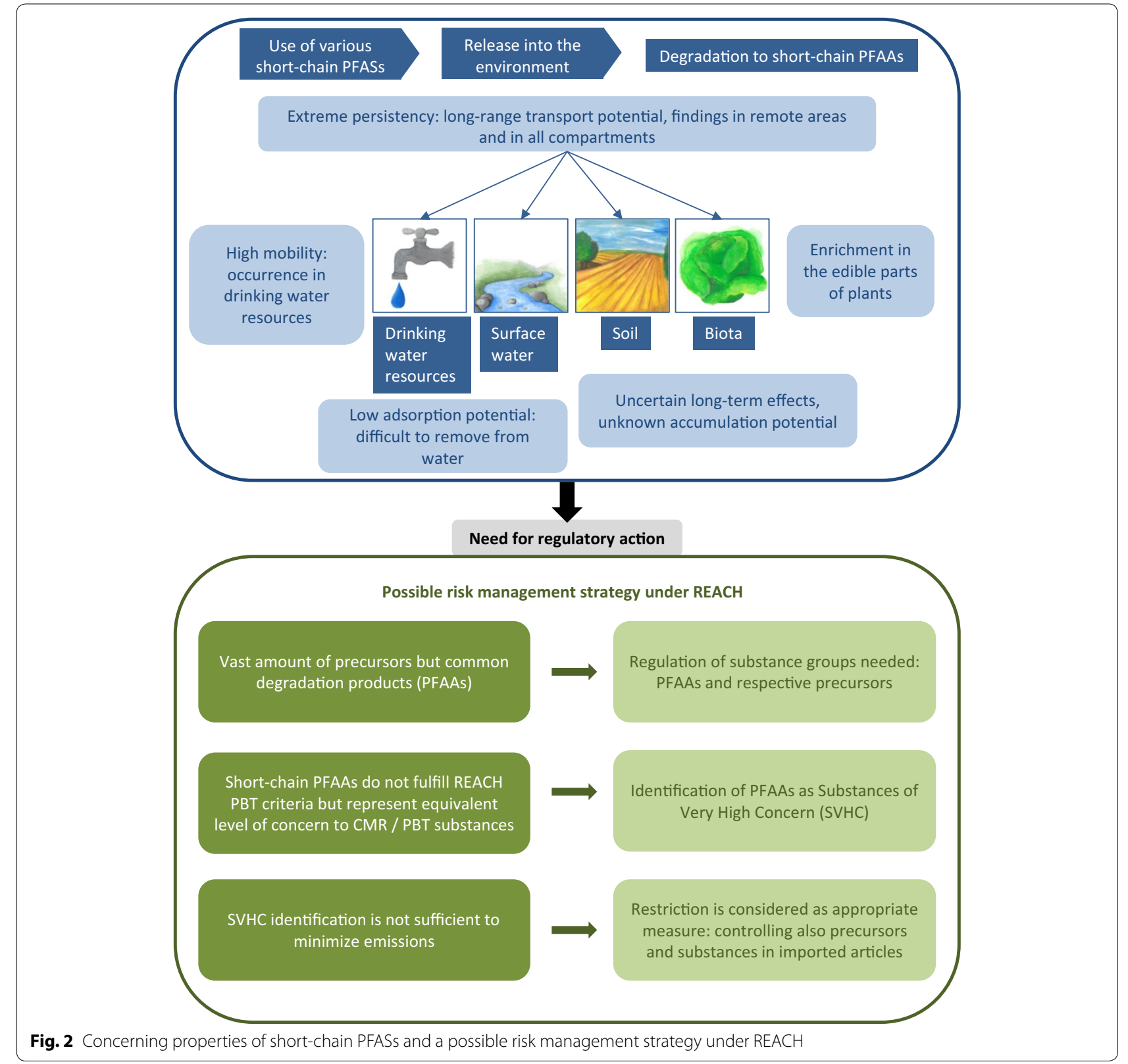

action to prevent further emission, the adverse effects will continue. The extreme persistence and other intrinsic properties (e.g., low adsorption potential) of shortchain PFASs unquestionable fulfill the second concern. In practice, this is shown in the "case example Rastatt". The first issue, that long-term effects cannot be estimated with sufficient accuracy, is in case of vPvB substances met by the very high bioaccumulation potential. Shortchain PFASs do not fulfill the criteria according to Annex XIII of the REACH Regulation for being bioaccumulative. However, as they will not degrade in the environment, there is a permanent and irreversible exposure of organisms. With ongoing emission, the environmental concentrations of short-chain PFASs will most probably increase, due to the lack of degradation and the fact that emerging emissions come on top of already released amounts resulting in an accumulation in certain environmental compartments. There is a high uncertainty about the toxicity of short-chain PFASs, especially regarding long-term effects (see "Overview of concerns of short-chain PFAAs"). If emissions continue and environmental concentrations of short-chain PFASs exceed a certain limit, it seems very likely that adverse effects may occur. Even if the releases of short-chain PFASs will stop 
immediately, the already emitted short-chain PFASs do irreversibly remain in the environment (see "Case example Rastatt"). These considerations and the additional concerns, such as enrichment in the edible parts of plants and the accumulation in water resources (see "Overview of concerns of short-chain PFAAs"), show that shortchain PFASs are of equivalent level of concern compared to $\mathrm{PBT} / \mathrm{vPvB}$ substances.

\section{Conclusion}

Short-chain PFASs are increasingly used and are considered to have properties of very high concern according to Article 57(f) of the REACH Regulation: They are of equivalent level of concern to PBT or $\mathrm{vPvB}$ substances. The outlined concerns related to short-chain PFASs, the already existing pollution, i.e., locally restricted very high pollutions (e.g., Rastatt and Uppsala) and global pollutions due to historical emissions, and very likely further increasing concentrations in the environment and biota illustrate that a fast regulation is mandatory. In accordance with the regulation of long-chain PFASs, the most effective way constitutes an SVHC identification of the short-chain PFAAs followed by a restriction, allowing also the regulation of precursors. The SVHC identification is not a prerequisite but will be advantageous, as the concerns attributed to short-chain PFASs do not comply with the "classical" concerns considered in the REACH Regulation and need to be clearly defined. In addition to a regulation by authorities, voluntary measures by industry could contribute substantially in reducing the emissions of short-chain PFASs.

\section{Methods}

A literature review was conducted to obtain available information on short-chain PFASs. The concerns of short-chain PFASs and its equivalent level of concern with regard to the REACH Regulation were discussed and the concern was specified at a workshop in Berlin, organized by the German Environment Agency (UBA) in October 2016. Regulatory experts and scientists from different EEA Member States, the European Commission, the European Chemicals Agency, USA and Australia participated.

\footnotetext{
Abbreviations

CMR: carcinogenic, mutagenic or toxic for reproduction; EEA: European Economic Area; $\mathrm{K}_{\mathrm{OA}}$ : octanol-air partition coefficient; $\mathrm{K}_{\mathrm{OC}}$ : organic carbon-water partition coefficient; $\mathrm{K}_{\mathrm{OW}}$ : octanol-water partition coefficient; PBT: persistent, bioaccumulative and toxic; PFAA: perfluoroalkyl acid; PFASs: per- and polyfluoroalkyl substances; PFBA: perfluorobutanoic acid; PFBS: perfluorobutane sulfonic acid; PFHXA: perfluorohexanoic acid; PFOA: perfluorooctanoic; PFOS: perfluorooctane sulfonic acid; $\mathrm{PK}_{\mathrm{a}}$ : acid dissociation constant; POP: persistent organic pollutant; REACH: European Chemicals Regulation, EC No. 1907/2006, Registration, Evaluation and Authorization of Chemicals; SVHC: substance of very high concern; $\vee \mathrm{PVB}$ : very persistent and very bioaccumulative.
}

Authors' contributions

SB, ÉF, CS, LV and ABE contributed in equal parts to this publication. This paper does not necessarily reflect the opinion or the policies if the German Federal Environment Agency. All authors read and approved the final manuscript.

\section{Acknowledgements}

The authors thank the participants of the workshop for authorities on shortchain PFASs in October 2016 hosted by the German Environment Agency for their valuable input in assessing the concerns of short-chain PFASs. We appreciate Christoph Schulte for his support and valuable ideas and Frauke Stock for valuable comments on earlier versions of this manuscript. Furthermore, we thank Chiara Rippe for drawing the pictures in Fig. 2.

\section{Competing interests}

The authors declare that they have no competing interests.

Availability of data and materials

All relevant data are available in the references cited.

Consent for publication

Not applicable.

Ethics approval and consent to participate

Not applicable.

\section{Publisher's Note}

Springer Nature remains neutral with regard to jurisdictional claims in published maps and institutional affiliations.

Received: 12 October 2017 Accepted: 17 January 2018

Published online: 27 February 2018

References

1. Kirsch P (2013) Modern fluoroorganic chemistry: synthesis, reactivity, applications. Wiley, Hoboken

2. Siegemund G, Schwertfeger W, Feiring A, Smart B, Behr F, Vogel H, McKusick B, Kirsch P (2000) Fluorine compounds, organic. Ullmann's encyclopedia of industrial chemistry. Wiley-VCH Verlag GmbH \& Co. KGaA, Weinheim

3. Buck RC, Franklin J, Berger U, Conder JM, Cousins IT, De Voogt P, Jensen AA, Kannan K, Mabury SA, van Leeuwen SP (2011) Perfluoroalkyl and polyfluoroalkyl substances in the environment: terminology, classification, and origins. Integr Environ Assess Manag 7:513-541

4. Swedish Chemicals Agency (2015) Occurrence and use of highly fluorinated substances and alternatives. www.kemi.se/en/global/rapporter/2015/report-7-15-occurrence-and-use-of-highly-fluorinatedsubstances-and-alternatives.pdf. Accessed 15 Jan 2018

5. Gremmel C, Frömel T, Knepper TP (2016) Systematic determination of perfluoroalkyl and polyfluoroalkyl substances (PFASs) in outdoor jackets. Chemosphere 160:173-180

6. Eriksson U, Haglund P, Kärrman A (2017) Screening of PFASs in sludge and water from waste water treatment plants. Swedish Chemicals Agency. http://urn.kb.se/resolve?urn=urn:nbn:se:naturvardsverket:diva-6900. Accessed 15 Jan 2018

7. Wang Z, Cousins IT, Scheringer M, Buck RC, Hungerbühler K (2014) Global emission inventories for (4-C14 perfluoroalkyl carboxylic acid (PFCA) homologues from 1951 to 2030, Part I: production and emissions from quantifiable sources. Environ Int 70:62-75

8. Washington JW, Jenkins TM, Rankin K, Naile JE (2015) Decades-scale degradation of commercial, side-chain, fluorotelomer-based polymers in soils and water. Environ Sci Technol 49(2):915-923

9. Fischer S, Lilja K, Ahrens L, Wiberg K (2016) Poly- and perfluoroalkyl substances on the market and in the Swedish environment. Norman Bull $5: 6-9$ 
10. Houde M, Martin JW, Letcher RJ, Solomon KR, Muir DC (2006) Biological monitoring of polyfluoroalkyl substances: a review. Environ Sci Technol 40:3463-3473

11. Giesy JP, Kannan K (2001) Global distribution of perfluorooctane sulfonate in wild life. Environ Sci Technol 35:1339-1342

12. Lau C, Butenhoff JL, Rogers JM (2004) The developmental toxicity of perfluoroalkyl acids and their derivatives. Toxicol Appl Pharmacol 198:231-241

13. Wang Z, Cousins IT, Scheringer M, Hungerbühler K (2013) Fluorinated alternatives to long-chain perfluoroalkyl carboxylic acids (PFCAs), perfluoroalkane sulfonic acids (PFSAs) and their potential precursors. Environ Int 60:242-248

14. Cousins IT, Kong D, Vestergren R (2011) Reconciling measurement and modelling studies of the sources and fate of perfluorinated carboxylates. Environ Chem 8(4):339-354

15. Wang Z, DeWitt JC, Higgins CP, Cousins IT (2017) A never-ending story of per-and polyfluoroalkyl substances (PFASs)? Environ Sci Technol 51:2508-2518

16. Blum A, Balan SA, Scheringer M, Trier X, Goldenman G, Cousins IT, Diamond M, Fletcher T, Higgins C, Lindeman AE (2015) The Madrid statement on poly-and perfluoroalkyl substances (PFASs). Environ Health Perspect 123:A107-A111

17. Scheringer $M$, Trier $X$, Cousins IT, de Voogt P, Fletcher T, Wang Z, Webster TF (2014) Helsingør statement on poly-and perfluorinated alkyl substances (PFASs). Chemosphere 114:337-339

18. Bowman JS (2015) Fluorotechnology is critical to modern life: the FluoroCouncil counterpoint to the Madrid Statement. Environ Health Perspect 123:A112

19. Schwanz TG, Llorca M, Farré M, Barceló D (2016) Perfluoroalkyl substances assessment in drinking waters from Brazil, France and Spain. Sci Total Environ 539:143-152

20. Ahrens L. RJ, Axelson S., Kallenborn R (2016) Source tracking and impact of per- and polyfluoroalkyl substances at Svalbard. Svalbard Environ Prot Fund. https://www.sysselmannen.no/link/036987d037924f23a96a0a0530 4596f3.aspx. Accessed 15 Jan 2018

21. Gellrich V, Brunn H, Stahl T (2013) Perfluoroalkyl and polyfluoroalkyl substances (PFASs) in mineral water and tap water. J Environ Sci Health A Tox Hazard Subst Environ Eng 48:129-135

22. Llorca M, Farre M, Pico Y, Muller J, Knepper TP, Barcelo D (2012) Analysis of perfluoroalkyl substances in waters from Germany and Spain. Sci Total Environ 431:139-150

23. Lorenzo M, Campo J, Farré M, Pérez F, Picó Y, Barceló D (2016) Perfluoroalkyl substances in the Ebro and Guadalquivir river basins (Spain). Sci Total Environ 540:191-199

24. Shafique U, Schulze S, Slawik C, Böhme A, Paschke A, Schüürmann G (2017) Perfluoroalkyl acids in aqueous samples from Germany and Kenya. Environ Sci Pollut Res 24:11031-11043

25. Kirchgeorg T, Dreyer A, Gabrieli J, Kehrwald N, Sigl M, Schwikowski M, Boutron C, Gambaro A, Barbante C, Ebinghaus R (2013) Temporal variations of perfluoroalkyl substances and polybrominated diphenyl ethers in alpine snow. Environ Pollut 178:367-374

26. GebbinkWA, Bignert A, Berger U (2016) Perfluoroalkyl Acids (PFAAs) and selected precursors in the Baltic Sea environment: do precursors play a role in food web accumulation of PFAAs? Environ Sci Technol 50:6354-6362

27. Klein M, Wanner A, Körner W, Sengl M, Diemer J, Lepper H (2016) Untersuchung zur Akkumulation verschiedener persistenter Schadstoffe in terrestrischen Wildtieren (in German). Bayerisches Landesamt für Umwelt. http://www.bestellen.bayern.de/shoplink/Ifu_all_00136.htm. Accessed $15 \operatorname{Jan} 2018$

28. Poulsen $P B$, Jensen $A A$, Wallström E, Aps E (2005) More environmentally friendly alternatives to PFOS-compounds and PFOA. Danish Ministry of the Environment, project no. 1013. http://www2.mst.dk/Udgiv/publications/2005/87-7614-668-5/pdf/87-7614-669-3.pdf. Accessed 15 Jan 2018

29. Kotthoff M, Müller J, Jürling H, Schlummer M, Fiedler D (2015) Perfluoroalkyl and polyfluoroalkyl substances in consumer products. Environ Sci Pollut Res 22:14546-14559

30. Li L, Liu J, Hu J, Wania F (2017) Degradation of fluorotelomer-based polymers contributes to the global occurrence of fluorotelomer alcohol and perfluoroalkyl carboxylates: A combined dynamic substance flow and environmental fate modeling analysis. Environ Sci Technol 51(8):4461-4470

31. Norwegian Environment Agency (2017) Investigation of sources to PFBS in the environment. M-759/2017. http://www.miljodirektoratet.no/Documents/publikasjoner/M759/M759.pdf. Accessed 15 Jan 2018

32. Kjølholt J, Jensen A, Warming M (2015) Short-chain Polyfluoroalkyl Substances (PFAS): a literature review of information on human health effects and environmental fate and effect aspects of short-chain PFAS. Danish Ministry of the Environment. Project no. 1707. https://www2.mst. dk/Udgiv/publications/2015/05/978-87-93352-15-5.pdf. Accessed 15 Jan 2018

33. Gyllenhammar I, Berger U, Sundström M, McCleaf P, Eurén K, Eriksson S, Ahlgren S, Lignell S, Aune M, Kotova N (2015) Influence of contaminated drinking water on perfluoroalkyl acid levels in human serum: a case study from Uppsala, Sweden. Environ Res 140:673-683

34. Hagenaars A, Meyer I, Herzke D, Pardo B, Martinez P, Pabon M, De Coen W, Knapen D (2011) The search for alternative aqueous film forming foams (AFFF) with a low environmental impact: physiological and transcriptomic effects of two Forafac ${ }^{\circledR}$ fluorosurfactants in turbot. Aquat Toxicol 104(3):168-176

35. UNEP (2016) Consolidated guidance on alternatives to perfluorooctane sulfonic acid and its related chemicals. http://chm.pops.int/lmplementation/PFOS/Guidance/tabid/5225/Default.aspx. Accessed 15 Jan 2018

36. Herzke D, Olsson E, Posner S (2012) Perfluoroalkyl and polyfluoroalkyl substances (PFASs) in consumer products in Norway: a pilot study. Chemosphere 88:980-987

37. Fujii Y, Harada KH, Koizumi A (2013) Occurrence of perfluorinated carboxylic acids (PFCAs) in personal care products and compounding agents. Chemosphere 93:538-544

38. Parsons JR, Sáez M, Dolfing J, de Voogt P (2008) Biodegradation of perfluorinated compounds. Rev Environ Contam Toxicol 196:53-71

39. Vierke L, Staude C, Biegel-Engler A, Drost W, Schulte C (2012) Perfluorooctanoic acid (PFOA) - main concerns and regulatory developments in Europe from an environmental point of view. Environ Sci Eur 24:16

40. D'Agostino LA, Mabury SA (2017) Aerobic biodegradation of two fluorotelomer sulfonamide-based aqueous film forming foam components produces perfluoroalkyl carboxylates. Environ Toxicol Chem 36:2012-2021

41. Cousins IT, Vestergren R, Wang Z, Scheringer M, McLachlan MS (2016) The precautionary principle and chemicals management: the example of perfluoroalkyl acids in groundwater. Environ Int 94:331-340

42. Wang Z, MacLeod M, Cousins IT, Scheringer M, Hungerbühler K (2011) Using COSMOtherm to predict physicochemical properties of poly-and perfluorinated alkyl substances (PFASs). Environ Chem 8:389-398

43. Vierke L, Möller A, Klitzke S (2014) Transport of perfluoroalkyl acids in a water-saturated sediment column investigated under near-natural conditions. Environ Pollut 186:7-13

44. Zhao P, Xia X, Dong J, Xia N, Jiang X, Li Y, Zhu Y (2016) Short-and longchain perfluoroalkyl substances in the water, suspended particulate matter, and surface sediment of a turbid river. Sci Total Environ 568:57-65

45. Ahrens $L$ (2011) Polyfluoroalkyl compounds in the aquatic environment: a review of their occurrence and fate. J Environ Monit 13:20-31

46. Boiteux V, Dauchy X, Bach C, Colin A, Hemard J, Sagres V, Rosin C, Munoz J-F (2017) Concentrations and patterns of perfluoroalkyl and polyfluoroalkyl substances in a river and three drinking water treatment plants near and far from a major production source. Sci Total Environ 583:393-400

47. Zhang C, Yan H, Li F, Hu X, Zhou Q (2013) Sorption of short-and longchain perfluoroalkyl surfactants on sewage sludges. J Hazard Mater 260:689-699

48. Lundgren S (2014) Evaluation of the efficiency of treatment techniques in removing perfluoroalkyl substances from water. Dissertation, Uppsala University. http://urn.kb.se/resolve?urn=urn:nbn:se:uu:diva-231195

49. Rahman MF, Peldszus S, Anderson WB (2014) Behaviour and fate of perfluoroalkyl and polyfluoroalkyl substances (PFASs) in drinking water treatment: a review. Water Res 50:318-340

50. Soriano Á, Gorri D, Urtiaga A (2017) Efficient treatment of perfluorohexanoic acid by nanofiltration followed by electrochemical degradation of the NF concentrate. Water Res 112:147-156 
51. Llorca M, Farré M, Tavano MS, Alonso B, Koremblit G, Barceló D (2012) Fate of a broad spectrum of perfluorinated compounds in soils and biota from Tierra del Fuego and Antarctica. Environ Pollut 163:158-166

52. Kirchgeorg T, Dreyer A, Gabrielli P, Gabrieli J, Thompson L, Barbante C, Ebinghaus R (2016) Seasonal accumulation of persistent organic pollutants on a high altitude glacier in the Eastern Alps. Environ Pollut 218:804-812

53. Lam JC, Lyu J, Kwok KY, Lam PK (2016) Perfluoroalkyl Substances (PFASs) in marine mammals from the South China Sea and their temporal changes 2002-2014: Concern for alternatives of PFOS? Environ Sci Technol 50:6728-6736

54. Shiwaku Y, Lee P, Thepaksorn P, Zheng B, Koizumi A, Harada KH (2016) Spatial and temporal trends in perfluorooctanoic and perfluorohexanoic acid in well, surface, and tap water around a fluoropolymer plant in Osaka, Japan. Chemosphere 164:603-610

55. Land M, de Wit CA, Cousins IT, Herzke D, Johansson J, Martin JW (2017) What is the effect of phasing out long-chain per-and polyfluoroalkyl substances on the concentrations of perfluoroalkyl acids and their precursors in the environment? A systematic review protocol. Environ Evid 4(1):3

56. Renner R (2006) The long and the short of perfluorinated replacements. Environ Sci Technol 40:12-13

57. Ahrens L, Bundschuh M (2014) Fate and effects of poly- and perfluoroalkyl substances in the aquatic environment: a review. Environ Toxicol Chem 33:1921-1929

58. Chengelis CP, Kirkpatrick JB, Myers NR, Shinohara M, Stetson PL, Sved DW (2009) Comparison of the toxicokinetic behavior of perfluorohexanoic acid (PFHXA) and nonafluorobutane-1-sulfonic acid (PFBS) in cynomolgus monkeys and rats. Reprod Toxicol 27:400-406

59. Gannon SA, Johnson T, Nabb DL, Serex TL, Buck RC, Loveless SE (2011) Absorption, distribution, metabolism, and excretion of [1-14 C]-perfluorohexanoate ([14 C]-PFHx) in rats and mice. Toxicology 283:55-62

60. Numata J, Kowalczyk J, Adolphs J, Ehlers S, Schafft H, Fuerst P, MüllerGraf C, Lahrssen-Wiederholt M, Greiner M (2014) Toxicokinetics of seven perfluoroalkyl sulfonic and carboxylic acids in pigs fed a contaminated diet. J Agric Food Chem 62:6861-6870

61. Nilsson H, Kärrman A, Westberg H, Rotander A, Van Bavel B, Lindström G (2010) A time trend study of significantly elevated perfluorocarboxylate levels in humans after using fluorinated ski wax. Environ Sci Technol 44:2150-2155

62. Bischel HN, MacManus-Spencer LA, Zhang C, Luthy RG (2011) Strong associations of short-chain perfluoroalkyl acids with serum albumin and investigation of binding mechanisms. Environ Toxicol Chem $30: 2423-2430$
63. Chen Y-M, Guo L-H (2009) Fluorescence study on site-specific binding of perfluoroalkyl acids to human serum albumin. Arch Toxicol 83:255

64. Bogdanska J, Sundström M, Bergström U, Borg D, Abedi-Valugerdi M, Bergman Å, DePierre J, Nobel S (2014) Tissue distribution of 35S-labelled perfluorobutanesulfonic acid in adult mice following dietary exposure for 1-5 days. Chemosphere 98:28-36

65. Burkemper JL, Aweda TA, Rosenberg AJ, Lunderberg D, Peaslee GF, Lapi SE (2017) Radiosynthesis and biological distribution of [18F]-labeled perfluorinated alkyl substances. Environ Sci Technol Lett 4:211-215

66. Lilienthal H, Dieter HH, Hölzer J, Wilhelm M (2017) Recent experimental results of effects of perfluoroalkyl substances in laboratory animals-relation to current regulations and guidance values. Int J Hyg Environ Health 220:766-775

67. Blaine AC, Rich CD, Hundal LS, Lau C, Mills MA, Harris KM, Higgins CP (2013) Uptake of perfluoroalkyl acids into edible crops via land applied biosolids: field and greenhouse studies. Environ Sci Technol 47:14062-14069

68. Felizeter S, McLachlan MS, de Voogt P (2012) Uptake of perfluorinated alkyl acids by hydroponically grown lettuce (Lactuca sativa). Environ Sci Technol 46:11735-11743

69. Felizeter S, McLachlan MS, De Voogt P (2014) Root uptake and translocation of perfluorinated alkyl acids by three hydroponically grown crops. J Agric Food Chem 62:3334-3342

70. Müller CE, De Silva AO, Small J, Williamson M, Wang X, Morris A, Katz S, Gamberg M, Muir DC (2011) Biomagnification of perfluorinated compounds in a remote terrestrial food chain: lichen-caribou-wolf. Environ Sci Technol 45:8665-8673

71. Navarro I, de la Torre A, Sanz P, Pro J, Carbonell G, de los Ángeles Martínez M (2016) Bioaccumulation of emerging organic compounds (perfluoroalkyl substances and halogenated flame retardants) by earthworm in biosolid amended soils. Environ Res 149:32-39

72. Citizen information Rastatt. http://www.landkreis-rastatt.de/,Lde/PFC. html. Accessed 15 Jan 2018

73. German Environment Agency (2017) Fortschreibung der vorläufigen Bewertung von per-und polyfluorierten Chemikalien (PFC) im Trinkwasser (in German). Bundesgesundheitsblatt 60:350-352

74. Blaine AC, Rich CD, Sedlacko EM, Hyland KC, Stushnoff C, Dickenson ER, Higgins CP (2014) Perfluoroalkyl acid uptake in lettuce (Lactuca sativa) and strawberry (Fragaria ananassa) irrigated with reclaimed water. Environ Sci Technol 48:14361-14368

\section{Submit your manuscript to a SpringerOpen ${ }^{\odot}$ journal and benefit from:}

- Convenient online submission

- Rigorous peer review

- Open access: articles freely available online

- High visibility within the field

- Retaining the copyright to your article

Submit your next manuscript at $\boldsymbol{\nabla}$ springeropen.com 